\title{
Crafted places/places for craft: pop-up and the politics of the 'crafted' city
}

\author{
Ella Harris
}

In recent years cities across the Global North have experienced the rapid rise of 'pop-up' culture; a trend for creating temporary places in disused sites and buildings. Pop-up has been widely promoted within the creative industries as providing cheap and flexible access to space and is now a popular format for craft makers and sellers. In this chapter I propose that examining pop-up's intersections with the craft economy offers important insights into craft's impact in contemporary cities. I explore pop-up as a geography through which craft's logics of one-off, handmade production and flexible labour are transforming the urban fabric. I consider how craft's emphasis on the unique and the handmade is, through pop-up, infused into the materiality of the city and how its labour logics of flexibility also find spatiotemporal form in pop-up's own versatile urban landscape. The growing intersection of craft and pop-up cultures, begs a pertinent question: if craft's sensibilities are being advanced and extended in the city through pop-up, then what does the politics of this 'crafted' city look like? More specifically; in a contemporary condition characterized by widespread precarity (Gill \& Pratt 2008), how does this extension of craft's logics reflect and shape assumptions about how cities should be lived, governed and reproduced?

Pop-up culture's shared sensibility with craft is clearly discernible. Pop-up sites are customarily handmade by their organizers; re-used materials are employed to craft personalized temporary spaces that, like craft products, are celebrated as one-off, DIY creations. Pop-up is also tied up with the same economic shifts towards post-Fordist economies within which craft is implicated. It is, like craft, an arena where 'flexible' work patterns are normalized and glamorized (Deslandes 2013; Ferreri 2015; Graziano \& Ferreri 2014). It is also rooted in the 'hipster' economy within which craft has been situated; a scene whose sensibilities include a return to domestic practices of 'making, cooking and growing' (Luckman 2015: 44) which can be partially understood in relation to the austerity aesthetics ensuing from the global financial crash (Jakob 2013; Luckman 2015; McRobbie 2013; Luckman 2013). 
Pop-up has, so far, been mainly considered in relation to creative cities (Mould 2014), artistic and cultural practice (Graziano \& Ferreri 2014; Harvie 2013), gentrification, (Harvie 2013; Mould 2014; Colomb 2012) and austerity urbanisms (Tonkiss 2013; Ferreri 2015). There has been little discussion of pop-up in relation to the craft economy, although the connections between the two are evident. In this chapter I approach pop-up and craft together through an empirical focus on Netil Market, a temporary place for craft production and consumption in Hackney, East London. In doing so, I consider craft as an urban imaginary and pop-up as a geography in which that imaginary is being embedded and reproduced. I argue that tracing the ways that craft's logics of production and consumption are engaged in pop-up culture will illuminate how those logics are shaping contemporary cities. Analysts of the craft economy have considered craft's role in creating communities (Gauntlett 2011) and shaping the identity of local areas and regions (Schenll \& Reese 2009; Thomas et al. 2012). Within this, craft's capacity to aestheticize post-industrial landscapes and intensify gentrification has been noted (Mathews \& Picton 2014; Dawkins 2011). This approach implicitly considers craft as an urban imaginary, in that its sensibilities are understood to transform how cities are imagined and produced. I bring this to the foreground, drawing pop-up culture into conversation with craft to consider how contemporary cities are themselves 'crafted' through the logics of the craft economy.

Building on discussion of Netil Market, I make two arguments about how craft and pop-up can be considered together to illuminate craft's urban imaginary and its politics. Firstly I address pop-ups as crafted places, exploring them as hand-made, customized sites and examining how they craft a particular kind of community. The aim of this section is to explore how craft's logics are mobilized by pop-up to 'craft' the urban environment in particular ways. Secondly, I explore pop-ups as places for craft. Having identified pop-up as a geography within which craft takes place, I argue that pop-up is an infrastructure for craft production which intensifies certain elements of craft's imaginary, in particular reinforcing the precarity of the craft economy.

\section{Crafted places}


Netil Market is located in Hackney, East London. Hackney is the epicentre of London's 'hipster' scene and, increasingly, a renowned area for craft production and retail (Schreiber \& Treggiden 2015). However, as rental prices in the area continue to rise there is growing financial pressure on Hackney's creative community and Netil Market is one of several sites that has sprung up to provide affordable, albeit temporary and makeshift, space for craft makers and sellers. As Sarah, the market manager, describes it, Netil Market is 'a space for creative professionals to conduct their work in a flexible environment ${ }^{1}$.' Occupying what was once a derelict carpark the market now contains several temporary units, mostly made from shipping containers, within which these professionals work and trade throughout the week. The container units line the perimeter of the market leaving space in the middle for other traders to join the market at the weekends, setting up on traditional counter market stalls. The market is affiliated with Netil House, one of three indoor spaces run by the company 'Eat Work Art' who 'transform empty buildings into studio spaces that become home to exceptional communities' (Eatworkart 2015). The traders in Netil Market explicitly position themselves as craft makers and sellers. Their websites promote their products as unique, emphasize the careful attention to their crafting, and celebrate craft's shift away from globalized production and retail towards the handmade (Luckman 2015; Sennett 2008; Dawkins 2011). Natalie from 'The Worshipful Little Shop of Spectacles' describes how she designs and crafts 'one off handmade spectacle frames...a rare art in a world of mass, factory-line production' (Theworshipfullittleshopofspectacles 2015) while Tatiana from the jewellery shop 'WeAreArrow' stresses that her jewellery is all handmade 'in her small workshop she and her husband built inside a shipping container' (WeAreArrow 2015).

Indeed, the use of customized shipping containers is crucial to the craft sensibilities of Netil Market. In this section I make two arguments about what it means to understand these pop-up sites as 'crafted', paying particular attention to the importance of shipping containers (a popular building material within pop-up culture) for the 'crafting' of place. Firstly, I argue that the use of container architectures extends the characteristics of craft products to the crafting of place, creating unique and

\footnotetext{
${ }^{1}$ All quotations from Sarah relate to an interview conducted in London Fields on 26 January 2015
} 
personal units, which reinforce the creative identities of the traders. It is increasingly commonplace to characterize temporary and mobile architectures as 'crafted' (the 'office for crafted architecture' in Southwark, South London is an interesting example of this') and I consider how the units in Netil Market could be considered as crafted places. Secondly I argue that the symbolic value of containers is also crucial to the 'crafting' of place, which takes place in Netil Market and specifically relates to the crafting of community.

To address my first point, that container architectures extend the logics of craft into the production of place, it is easy to see how the container units in Netil Market embody craft's sense of the unique and the personal. Most of the containers were bought from the company 'Bell'ii who specialize in container conversions and each trader has customized their container to expresses the style and ethos of their business, making architectural as well as decorative adjustments. For instance, Tatiana's container is fitted with an internal wall of white painted wooden boards and shelves made of reclaimed wood. She uses a log for a stool. Bare light bulbs hang on exposed wires and the inside is decorated with leaves, reiterating the aesthetics of her jewellery which, at the moment is inspired by 'found plant parts' including 'seeds, pods and petals' (WeAreArrow 2015). 


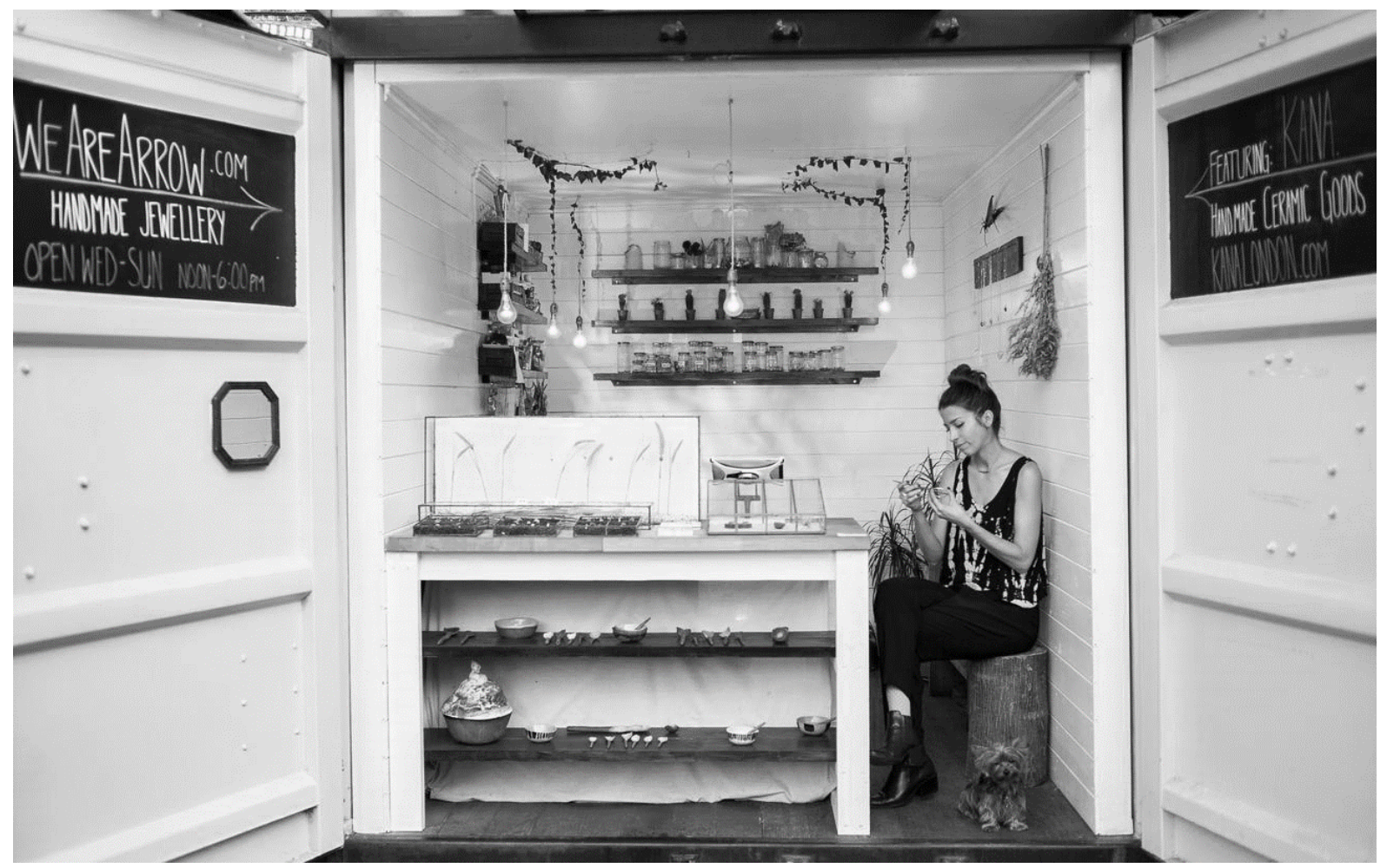

Fig 1: Tatiana in her studio. Photograph by Jan Vrhovnik, 2015

In contrast, another container used by The General's Barber Shop's, a hairdresser, is decorated to feel more like an old fashioned North American ranch workshop. Brooms, metal dust pans and hair brushes hang from chains and products are stored in chests. The barber chairs and bottles for shampoo and lotion are all vintage or at least, made to look old fashioned. On top of the container a typical red, blue and white stripy barber shop pole has been fitted. Customers can also buy beers, which the barbers brew themselves. The pseudo-workshop environment that 'The General's Barber' shop has created affiliates their hairdressing practice with craft production. The effort put into the unit's design, as well as the brewing of their own (craft) beer, is aesthetic labour (Hracs \& Leslie 2014; Warhurst \& Dennis 2009) which assists in the crafting of identity for the barber shop.

The upkeep of a particular 'look' is crucial within the creative industries, where crafting an identity is equally as important as creating a product or service (Hracs \& Leslie 2014; Luckman 2013). In Netil Market this is clearly achieved through the customization of containers. The personalized 
design and decoration of the units extends the sense of intimacy with the makers that customers find in their handmade products, creating places that are also 'imbued with touch' (Luckman 2015: 2). The units perform a version of what Thrift has described as 'worlding'; the construction of a 'digestible environment' (Thrift 2008: 13) that captures the imagination of the consumer. Inside each container a stylized world is created of which the traders are the epicentre. Going to 'The General's Barber Shop' or browsing Tatiana's products is to enter into a world infused with their creative identities and the allure of the products and services stems from the potential to consume a small part of this world.

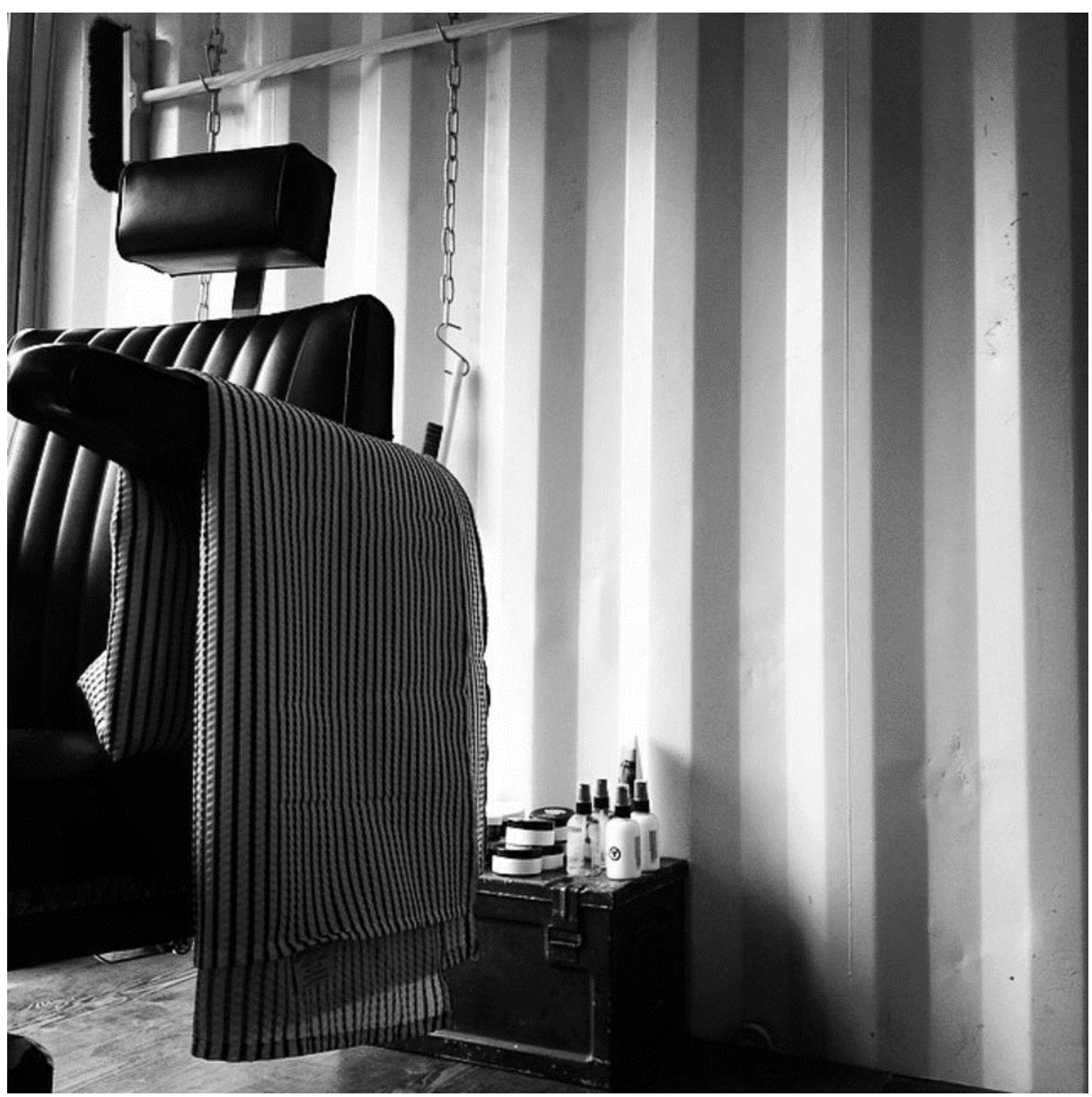

Fig 2. The General's Barber Shop. Photograph by Lee Wells

As well as decorative adjustments to the containers, the symbolic value of their transformation from industrial, mass produced objects to handmade, personalized units is also important to the crafting of place and 'worlding' of the products. Shipping containers are routinely positioned as 
emblematic of commercial standardization and related imaginaries of 'smooth space' (Martin 2013). It is argued that the intermodality of containers enables goods to travel seamlessly across space-time and thereby smooth's over the heterogeneous characteristics of the environments they traverse (Martin 2013). Moreover, the standardized design of the boxes mean that 'one is never privy to the contents...Everything is hidden from view to the extent that all that is given to the eye is the spectacle of efficiency' (Martin 2012: 154). In stark contrast, the containers in Netil Market aim to evoke individuality (although there is an irony to this given the increasing ubiquity of container spaces in London). Where the exteriors of industrial containers hide the contents of the box, those in Netil Market signpost their contents even when locked up as, for example, achieved by the barber sign on top of 'The General's Barber' shop. The customizing of the containers thereby creates 'crafted places' which mirror the movement of craft products away from the logics of mass production towards the unique and reinforce the uniqueness of those products by creating a distinctive world around them. Similarly, while cargo containers in global circulation smooth over the heterogeneous characteristics of environments in Netil Market the containers are used to craft an environment that stands out from routine city spaces.

The reason that containers are so widely available for repurposing as architectures is because 'it is often cheaper for exporting countries to make new containers than it is to ship the empty ones back again' (Parker 2012: 9). Overproduction is required for economic efficiency, so surplus containers pile up and are repurposed for 'housing, office space, pop-up events and so on' (Parker 2012: 9). During recession in particular 'there is an oversupply of containers' (13), which explains why temporary container architectures have become so popular since 2008. That the containers are a waste product of globalized commercial production is important to the second kind of crafting of place which Netil Market is implicated in; the crafting of community.

It has been argued that the ruins of capitalist infrastructures provide fissures within which craft has the power to experiment with alternative forms of community and economy (Bratich \& Brush 2011) and this is certainly the imaginary engaged by the repurposing of containers in Netil Market. 
Gregson and Crewe have suggested that the former meanings of a second-hand object can be reimagined, taking on new significance in the re-used or repurposed product (Gregson \& Crewe 2003). Here, the meanings of containers are reimagined through their customization. Once emblematic of wasteful hyperproduction, in pop-up spaces the containers can come to connote practices of mindful re-use and slow, small scale production. As has been argued, craft production reacts to anxieties around waste with a focus on recycling (Harrod 2013). This has particular purchase at a time of recession and austerity during which a 'culture of thrift' has emerged (Potter \& Claire 2013: 155) and been taken up, in particular, within the hipster scene. Despite the way that trends for waste reduction and DIY have been highly commercialized, not just within the urban hipster scene but also in popular culture and television (Luckman 2015; Potter \& Claire 2013) they evoke a 'vague anti-capitalist positioning' (Potter \& Claire 2013: 162). This is attractive to the many young creative people disenfranchised and disillusioned by recession. The repurposed containers, in evoking this imaginary of re-use, thereby draw together a community of craft traders seeking to share in that ethos. Indeed, there is a pervasive emphasis on environmental sustainability in the food and drink produced and sold in Netil Market, as well as from the cycle shack who promote biking as an alternative form of transport in the city. Suwun who also operate out of a container, run a 'Gender-neutral ethical lifestyle shop' which mainly sells clothing, extending the 'utopian' promises of craft (Banks 2010: 311) to tackle contemporary gender norms embedded in consumption.

Of course, while Netil Market crafts a community which, typical of hipster economies, has 'an aesthetics informed by environmental and labour concerns' (Luckman 2015: 41), the same aesthetics are implicated in the crafting of geographies of exclusion. These days Hackney is almost synonymous with gentrification. As the epicentre of London's hipster economy, and an increasingly popular residential location for upper middleclass professionals and families, it has undergone significant changes over recent decades (Butler et al. 2013; Duman 2012). Sarah explains how Netil House occupies what was a community college before it became derelict and was squatted. She says that in the early days after Eat Work Art took the property over her boss would show people around 'with the 
light from his Nokia phone, promising they'd be a studio there if they put a deposit down'. The carpark that is now the market was also 'awful, completely overgrown', strewn with 'mattresses, syringes, the kind of things you'd expect in East London' but Sarah's predecessor cleaned it up and started to find traders to fill it.

This description of Netil House's take-over of a dilapidated site resonates with arguments that temporary, creative businesses act as urban pioneers which colonize formerly working class areas of the city (Colomb 2012; Harris 2015; Harvie 2013; Mould 2014; Luckman et al. 2008). In London, popup culture, and the 'meanwhile use lease' template (Gov.uk 2013) developed to facilitate it, has codified in policy and redevelopment discourse the repurposing of derelict spaces that has long taken place in the city. Temporary creative spaces like Netil Market now abound in East London and, while many are organized by small creative businesses, social enterprises or community groups the format 'now come[s] as readily to property developers, alert to the speculative possibilities' (Tonkiss 2013: 318) of temporary creative places. As such, pop-up has exacerbated the trajectories of gentrification which craft has long been implicated in (Mathews \& Picton 2014; Smith 1996) by helping to popularize the repurposing of derelict spaces for creative use. Indeed, Sarah recognizes that the success of the market has contributed to rapidly rising house prices in the immediate area. Approaching Netil Market as a crafted place therefore reveals the political contradictions embedded in craft's urban imaginary. The 'crafted' units in Netil Market are implicated in two conflicted forms of urban 'crafting'; firstly, the crafting of creative communities organized around craft's ethos of production and secondly, the crafting the exclusionary geographies of gentrification.

\section{Places for craft}

Having considered the pop-ups in Netil Market as 'crafted places' this section explores pop-up as a geography for craft. I address how pop-up, as a temporary and mobile infrastructure for craft production and consumption, helps craft businesses to mitigate some of the impacts of precarity while also cementing that precarity. It has been argued that craft 'creates slow space....at odds with the 
imperative towards hyperproduction' (Bratich \& Brush 2011: 236). At first glance this would seem to be confirmed by Netil Market where decommissioned containers, a direct result of that hyperproduction, are repurposed as units for the slow and careful making of craft goods and services. Yet, as Sharma has argued, imaginaries of 'slow' production and consumption are often based on unfounded and idealized assumptions and mask what are in reality precarious and demanding temporalities of labour (Sharma 2014). Indeed, a closer look at the spatiotemporal logics of crafted pop-up places troubles the notion that they offer an antidote to the temporalities of capitalist hyperproduction.

As is widely recognized, the craft economy is at the forefront of shifts towards 'flexible' labour and experiences of precarity are widespread (Banks et al. 2013; Gill \& Pratt 2008). Binge work patterns are usual, with dry spells punctuating intense periods of labour and securities such as sick pay and holiday pay are lacking. Yet regardless of oscillations in work, and importantly income, workers must be 'always on'; constantly putting energy into the maintenance of a business identity that 'becomes increasingly difficult' to separate from their personal lives and leisure time (Hracs \& Leslie 2014: 67). Pop-up culture provides an infrastructure which exacerbates these conditions of precarity. It is normal for pop-ups to occupy a space for only a few months, weeks, days or even hours, responding to availability. Furthermore under the terms of meanwhile lease contracts, pop-ups usually have short notice periods so can be easily evicted at any point. As a place for craft, pop-up therefore normalizes and intensifies craft's unstable temporalities and matches them with an unpredictable, 'flexible' geography (Harris 2015). Businesses get used to moving nomadically from site to site as and when cheap space is available.

Sjöholm has questioned the nature of the modern studio at a time when 'artistic practices' are increasingly 'nomadic', 'fragmented' and 'precarious' (Sjöholm 2013: 506) and in Netil Market, the craft makers mobilize the pop-up format to respond to this precarity with studios that are themselves nomadic; built from containers specifically designed to be moved and transported. Sarah was initially hesitant to allow too many containers in the market because of the growing ubiquity of container 
spaces (East London alone is also home to several including Boxpark, Containerville, Bootyard and Container City). But as she says 'the market is a transient thing, daily it changes [and] monthly we have new people coming in' and in these instances it is 'much easier to have a container'.

Designed to withstand transoceanic travel, containers are strong and secure. Although moving them does require forklifts containers do not need to be dismantled so can be relocated without risking damage. They can also be locked up anywhere they need to be left, keeping their contents safe from theft. As Egle, one of the owners of Suwun, explained to me in an interview 'you just lock the container door at night and that's it; nobody can get in'. In this way, containers provide an architecture for craft production and consumption which enables the traders to both withstand and succumb to the flux they face.

The nomadism that the pop-up format enables for craft practitioners, also relates to an expectation that craft makers and traders should be instrumental in making the city more efficient and resourceful. Containers, as used in pop-up, ironically create a revised version of the spectacle of efficiency' they evoke in geographies of mass production (Martin 2012). As Ferreri has argued, in post austerity London pop-up carries a 'moral imperative' to make use of 'waste spaces' at a time of '(alleged) social and economic scarcity' (Ferreri 2015). In a city where space is expensive and in high demand, and at a time when funding for creative projects is scarce, disused sites are framed as opportunities for temporary creative use which it would be wasteful not to take up. This emphasis on thrift and resourcefulness within pop-up culture resonates with craft's own imperatives to re-use and re/upcycle as well as to reduce the production of waste. As places for craft, pop-up extends craft's imaginary of waste and re-use to include a prerogative to re-use 'wasted' urban space-time. In doing so, I would argue, it also further precaritizes craft production in two mains ways.

Firstly, the way that pop-ups occupy 'wasted', interim space-times between more routine uses of sites can make them subservient to other investment cycles. One of the reasons that pop-ups are valued by stakeholders, such as, private landlords and local governments is because they are thought to attract investment to disused sites (Ferreri 2015). Indeed, this is why they are given short notice 
periods; so that they can be easily moved on when that investment is found. As such, pop-up is a precarious urban form; easily mobilized to rejuvenate a 'wasted' space-time but just as easily displaced when a more profitable use is identified. Sarah's comments on Netil Market confirm this sense of precarity. Asked about the future of Netil Market, Sarah points to the many new housing developments which surround it and suggests that the future of the market is uncertain as the space becomes increasingly desirable for investment. 'We only get brief opportunities to use these spaces', she comments 'before they're developed... And the way things are going around here, if there's any chance of developing it, it will be'. So, if pop-ups are increasingly providing spaces for craft to take place, then in doing so they are extending the precarity embedded in craft imaginaries by providing an infrastructure within which it is normal for craft businesses to be nomadic, temporary and, crucially, subservient to the prerogatives and time scales of investment.

Secondly, the use of pop-up as an infrastructure for craft also extends the way that labour is 'deterritorialized, dispersed and decentralised' (Gill \& Pratt 2008: 7) within the craft economy. The imperative within pop-up to seize 'wasted' space-times positions the whole city as a prospective site of work. In pop-up culture empty car parks, roof tops, shops after hours, gardens, parks, yards, derelict buildings and much more all become potential sites of labour. Within this imaginary it is the creative classes, including craft workers, who are expected to activate the latent work spaces of the city (Ferreri 2015). Pop-up's impetus for creative people to find and utilise such 'wasted' urban spaces makes the whole city a 'factory without walls' (Negri 1989: 79 in Gill \& Pratt 2008: 7). Furthermore, the discourse of 'waste' gives this expectation more weight, positioning it as an ethical prerogative (Ferreri 2015). The precarity of the craft economy is thus further intensified through pop-up. If leisure time and domestic space have already been colonized through its logics, then the way that craft is engaged by pop-up culture subsumes new urban geographies in to the 'social factory' (Gill \& Pratt 2008).

\section{Conclusions}


In this chapter I have approached craft and pop-up culture together through a focus on Netil Market as a crafted place and a place for craft. In doing so, I have illuminated ways that craft's urban imaginary is playing out in contemporary London. As we have seen, pop-ups are crafted places that carry craft's emphasis on the handmade and the one-off into the production of temporary urban sites. These crafted sites then have an important role in 'crafting communities' where this entails both the production of creative communities positioned against mass production and the crafting of geographies of exclusion. As places for craft, I have argued that container units give craft traders resilience in a city where craft work is increasingly nomadic and unstable. I have also suggested that, as an infrastructure for craft production and consumption, pop-up is extending the precarity of the craft economy. In particular, I have explored how pop-up is mobilized to produce a city in which spatiotemporal precarity for craft workers is normalized in order to favour the interests of larger scale investment, and in which any space-time is positioned as a potential site of labour.

Thinking about the common sensibilities of craft and pop-up, can also shed light on the purchase of both phenomenon in the contemporary moment. Craft has become so popular in recent years, both as a term and an aesthetic, that many argue it is now almost meaningless (Walker 2015), applied to practices that have little to do with craft in the traditional sense. The term 'pop-up' too seems to have lost in precision what it has rapidly gained in currency, often now used to refer to fairly long term developments or, conversely to things that are inherently temporary or mobile. This accusation that craft has become meaningless could certainly be levelled at businesses such as the barber shop in Netil Market as well as to the positioning of temporary architectural construction as a form of craft. Yet if these terms are becoming indicators of broad aesthetics, rather than descriptors of defined practices and products, this is in itself revealing. To me, what the loose usage of these terms suggests is that affiliation with craft or with pop-up is desired not only because of what doing craft or doing pop-up, in their purest sense, involve, but because of the value found in the narratives they offer. As the case of Netil Market shows, craft's pop-up geographies offer meaningful sites of labour to young people disenfranchised by economic crisis while at the same time playing into the 
prerogatives of developers and local governments by cheaply rebranding disused sites and normalising flexible labour. Given the utility of these terms for (positively) narrativizing precarious urban conditions their appeal in the contemporary economic climate is hardly surprising. Thinking about craft and popup together therefore helps to develop an understanding of how precarious urban conditions are being narrativized.

Pop-up is by no means the only geography in which the logics of craft production and consumption are visible. However, it is an arena in which the influence that craft's logics are having on the production and imagination of urban space are particularly clear. Thinking about pop-up culture as part of the craft economy can open up new ways of understanding craft's imaginary and, as this chapter has demonstrated, can elucidate what is at stake politically in craft's influence over cities.

\section{References}

Banks, M. (2010), 'Craft labour and creative industries', International Journal of Cultural Policy, 16 (3): 305-321.

Banks, M., Gill, R. \& Taylor, S. (2013). Theorizing Cultural Work, Labour, continuity and change in the cultural and creative industries, London, New York: Routledge.

Bratich, J. Z. \& Brush, H. M. (2011), 'Fabricating Activism: Craft-Work, Popular Culture, Gender', Utopian Studies, 22 (2): 233-260.

Butler, T., Hamnett, C. \& Ramsden, M. J. (2013), 'Gentrification, Education and Exclusionary Displacement in East London', International Journal of Urban and Regional Research, 37 (2): 556-575.

Colomb, C. (2012), 'Pushing the Urban Frontier: Temporary Uses of Space, City Marketing, and the Creative City', Journal of Urban Affairs, 34 (2): 131-152.

Dawkins, N. (2011), 'Do-It-Yourself: The Precarious Work and Postfemnist Politics of Handmaking (in) Detroit', Utopian Studies, 22 (2): 261-284.

Deslandes, A. (2013), 'Exemplary Amateurism, Thoughts on DIY Urbanism', Cultural Studies Review, 19 (1): 216-27.

Duman, A. (2012), 'Dispatches from 'the frontline of gentrification', City, 16 (6): 672-685.

Eatworkart. (2015), eatworkart. [Online]

Available at: http://eatworkart.com/about/what-we-do/

[Accessed 0707 2015].

Ferreri, M. (2015), 'The seductions of temporary urbanism', ephemera: theory \& politics in organization, 15 (1): 181-191. 
Gauntlett, D. (2011), Making is Connecting: The Social Meaning of Creativity, From DIY and Knitting to YouTube and Web 2.0. Cambridge, Malden: Polity Press.

Gill, R. \& Pratt, A. (2008), 'Precarity and Cultural Work: In the Social Factory? Immaterial Labour, Precariousness and Cultural Work', Theory, Culture \& Society , 25 (7-8): 1-30.

Gov.uk. (2013), Meanwhile use lease. [Online]

Available at: https://www.gov.uk/government/collections/meanwhile-use-leases-and-guidance-forlandlords

[Accessed 1908 2015].

Graziano, V. \& Ferreri, M. (2014), 'Passion without Objects Young Graduates and the Politics of Temporary Art Spaces', Recherches sociologiques et anthropologiques, Volume 2: 83-102.

Gregson, N. \& Crewe, L. (2003), Second Hand Cultures. Oxford and New York: Berg.

Harris, E. (2015), 'Navigating Pop-up Geographies: Urban Space-Times of Flexibility, Interstitiality and Immersion, Geography Compass, 9 (11): 592-603

Harrod, T. (2013), 'Visionary rather than practical': craft, art and material efficiency, Philosophical Transactions of The Royal Society, 371 (1986): 1-12.

Harvie, J. (2013), Fair Play. Hampshire: Palgrave Macmillan.

Henninger. (2015), Office for Crafted Architecture, http://www.ofca.co.uk/.Accessed 01/022016

Hracs, B. J. \& Leslie, D. (2014), 'Aesthetic labour in creative industries: the case of independent musicians in Toronto, Canada', Area, 1 (66-73): 46.

Jakob, D. (2013), 'Crafting your way out of the recession? New craft entrepreneurs and the global economic downturn', Cambridge Journal of Regions, Economy and Society, Volume 6: 127-140.

Luckman, S. (2013), 'The Aura of the Analogue in a Digital Age, Women's Crafts, Creative Markets and Home-Based Labour After Etsy', Cultural Studies Review, 19 (1): 249-270.

Luckman, S. (2015), Craft and the Creative Economy. New York: Palgrave Macmillan.

Luckman, S., Gibson, C. \& Lea, T. (2009), 'Mosquitoes in the mix: How transferable is creative city thinking?' Singapore Journal of Tropical Geography, 30 (1): 70-85

Martin, C. (2012), 'Controlling Flow: On the Logistics of Distributive Space', in A. Ballantyne \& C. L. Smith (eds), Architecture in the Space of Flows, London and New York: Routledge.

Martin, C. (2013), 'Shipping container mobilties, seamless compatibility, and the global surface of logistical integration', Environment and Planning A, Volume 45: 1021-1036.

Mathews, V. \& Picton, R. M. (2014), Intoxifying gentrification: brew pubs and the geography of postindustrial heritage, Urban Geography, 35 (3): 337-356.

McRobbie, A. (2013), 'Fashion matters Berlin; city-spaces, womens working lives, new social enterprise', Cultural Studies, 27 (6): 982-1010.

Mould, O. (2014), 'Tactical Urbanism: The New Vernacular of the Creative City', Geography Compass, 8 (8): 529-539.

Parker, M. (2012), 'Containerisation: Moving Things and Boxing Ideas', Mobilities: 1-20. 
Potter, L. \& Claire, W. (2013), 'Neoliberal Britain's Austerity Foodscape: Home Economics, Veg Patch Capitalism and Culinary Temporality', new formations: a journal of culture/theory/politics: 155-178.

Schenll, S. M. \& Reese, J. F. (2009), 'Microbreweries as Tools of Local Identity', Journal of Cultural Geography, 21 (1): 45-69.

Schreiber, C. \& Treggiden, K. (2015), Makers of East London. London: Hoxton Mini Press

Sennett, R. (2008), The Craftsman. London: Penguin.

Sharma, S. (2014), In the Meantime, Temporality and Cultural Politics. Durham and London: Duke University Press.

Sjöholm, J. (2013), 'The art studio as archive: tracing the geography of artistic potentiaity, progress and production', Cultural Geographies in Practice, 21 (3): 505-514.

Smith, N. (1996), The New Urban Frontier: Gentrification and the Revanchist City. London and New York: Routledge.

Theworshipfullittleshopofspectacles. (2015), theworshipfullittleshopofspectacles. [Online] Available at: http://www.theworshipfullittleshopofspectacles.com/handmade-frames/ [Accessed 2408 2015].

Thomas, N. J., Harvey, D. C. \& Hawkins, H. (2012), 'Crafting the Region: Creative Industries and Practices of Regional Space', Regional Studies, 47 (1): 75-88.

Thrift, N. (2008), 'The Material Practices of Glamour', Journal of Cultural Economy, 1 (1): 9-23.

Tonkiss, F. (2013), 'Austerity Urbanism and the makeshift city', City: analysis of urban trends, culture, theory, policy, action, 17 (3):312-324.

Walker, Daniela. (2015), 'The hipster is dead, let's start an anti-authenticity movement' Marketing Magazine available at http://www.marketingmagazine.co.uk/article/1366143/hipster-dead-letsstart-anti-authenticity-movement [Accessed 0102 2015].

Warhurst, Chris; Nickson, Dennis. (2009), 'Who's Got the Look?' Emotional, Aesthetic and Sexualized Labour in Interactive Services', Gender, Work \& Organization, 2009, 16 (3): 385-404

WeAreArrow. (2015), WeAreArrow. [Online]

Available at: http://www.wearearrow.com/about/

[Accessed 1808 2015].

\footnotetext{
i http://www.ofca.co.uk/

ii http://www.bellcontainer.co.uk/
} 